University of Montana

ScholarWorks at University of Montana

Fall 2010

\title{
I Miss the Hungry Years: Coping with Abundance
}

Albert Borgmann

University of Montana-Missoula, albert.borgmann@umontana.edu

Follow this and additional works at: https://scholarworks.umt.edu/philosophy_pubs

Part of the Philosophy Commons

Let us know how access to this document benefits you.

\section{Recommended Citation}

Borgmann, Albert, "I Miss the Hungry Years: Coping with Abundance" (2010). Philosophy Faculty

Publications. 13.

https://scholarworks.umt.edu/philosophy_pubs/13

This Article is brought to you for free and open access by the Philosophy at ScholarWorks at University of Montana. It has been accepted for inclusion in Philosophy Faculty Publications by an authorized administrator of ScholarWorks at University of Montana. For more information, please contact scholarworks@mso.umt.edu. 


\title{
I miss the hungry years: coping with abundance
}

\author{
Albert Borgmann \\ Regents Professor of Philosophy \\ UM-Missoula \\ Albert.Borgmann@umontana.edu
}

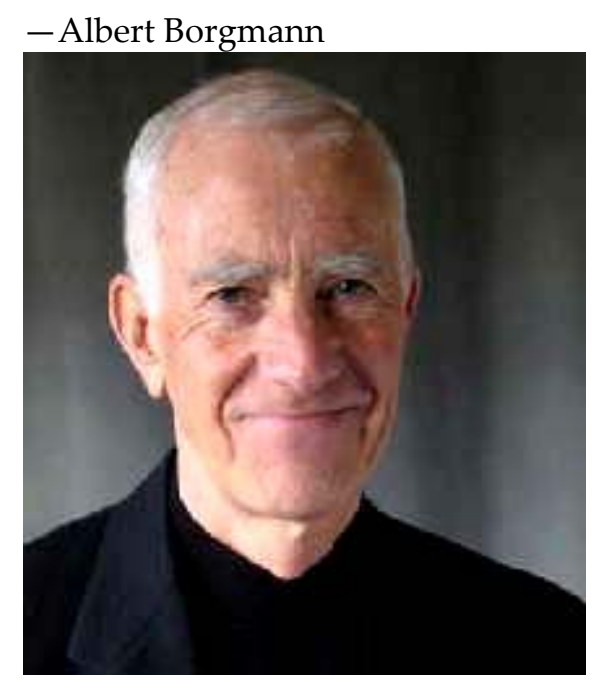

Information technology is a marvel of ingenuity and engineering. It's been widely admired and used; it's being advanced by inventiveness and competition; and it's being promoted by politicians and education experts. But there has also been research and discussion of the liabilities of information technology. The abundance of information has not, as one might have expected, made people generally more attentive and knowledgeable. On the contrary, distraction and ignorance are spreading. That has to worry people in higher education.

I won't rehearse the evidence of wide-spread ignorance and distraction./1/ Instead, I'll try to shed more light on the problem by calling attention to analogies between food and information. In particular, I'll suggest that what we are beginning to learn about how to cope with food we should apply to information.

Food, sex, and information must have been crucial to the evolution of humans. No doubt, some humans didn't care about food, were indifferent to sex, or were incurious. But the abstemious, frigid, or indolent presumably left fewer offspring and disappeared without a trace. We are the progeny of creatures who have always been hungry for food, sex, and news, and so are we.

In pre-modern circumstances, however, human voraciousness has always been met by relative scarcity, and thus overindulgence was for the most part impossible. But the culture of the advanced industrial countries 
gradually changed scarcity into abundance, first of food, then of information, and finally of sex. And now abundance has turned from a blessing into a curse.

My concern is with the abundance of information. I will set aside sex, and I will use food to illustrate a pathology and cure that are more evident in food and can help us to recognize problems with information that are more concealed if no less perilous. Food and information are large topics. But we can get a grip on what's crucial for information and education by paying attention to a pattern of development they share and that allows us to narrow our focus.

The trajectory of modern technology typically traces a path from the provision of basic and necessary commodities to the production of ever more refined and diverse consumption goods. That path is always traced by the conjoined processes of mechanization and commodification. An increasingly sophisticated and powerful machinery draws more and more goods and services out of the contexts of family and community and offers them at a price and in a variety that traditional producers can't rival.

If we trace the mechanical path of agriculture, we see the improvement of ploughs, the invention of mechanical reapers, the introduction of steam power, the spread of tractors until we reach the contemporary food industry with its computers, GPS devices, and its sophisticated biochemistry. The commodification trail leads from canned goods and mechanized bread baking to today's supermarket with its more than 40,000 different items.

The development of information technology led from the pony express to the railroad, from the manpowered printing press to the steam-powered rotary press, from the telegraph to the telephone, from radio to television, and in the last quarter of the last century to the computer revolution. Today the commodities of information are available on fine-grained and colored screens that are larger and smaller than ever.

The overall tendency, then, has been from scarcity by way of technological progress to an abundance of food and information. In our advanced industrial setting, people have a range of choice and a degree of control that amount to incredible power. You can summon most any food or information at any time and wherever you are. In fact the rhetoric of empowerment has always driven and celebrated the growing availability of food and information.

We have to be grateful for these developments, grateful to our ancestors 
who did incredibly hard and often crippling work to push the developments forward, grateful that we are spared the hunger, the illness, and the confinement that marked the lives of our forebears. But given the superlative successes of technology and the power it has lent us, we should expect more than the satisfaction of basic needs. We should see a powerful culture, a country of people who are physically vigorous and intellectually articulate, who are healthy and insightful.

Something went badly wrong, however. Instead of articulate vigor, we see physical and mental distension. We see shapeless bodies and distracted minds. We're also beginning to recognize what went wrong with food, and we should learn to apply what we have learned from the fate of food to the future of information.

In the United States, two thirds of the population are overweight or obese. Morbidity and mortality today are much more benign than they used to be. But what health and longevity we have is as much the result of medical scaffolding as it is of natural vigor. Many of the diseases that trouble our lives are self-inflicted through lack of exercise and bad nutrition. Bad nutrition? How can that be, given the variety and abundance of food? To understand what happened, we need to recognize the tendency of the machinery that has come between the fields and the mouth. Food has always been mediated through devices, at first through bow and arrow, through digging sticks and baskets, through fire and fermentation.

Until the middle of the nineteenth century, most of these tools were still under the direct control and within the direct experience of ordinary people. To produce the amount, the variety, and the attractiveness of today's mainstream food, a huge and sophisticated machinery is required. What comes out of the soil is distant raw material, distant in space, distant in shape and texture, and distant to our understanding of it all. But the final products are as close as they can be to our desires. They indulge the size of our appetites and our cravings for what's colorful, sweet, juicy, creamy, and salty.

Eating used to be the conclusion of an intricate and intelligible process, a lengthy sequence of steps we all had to take in greater or lesser part. It went from planting and raising to harvesting and slaughtering, to curing and storing, to preparing and cooking and then, finally to eating. It's plausible to assume that the only thing that really matters in this process is the final stage-putting food in our mouths. If we could dispense with all 
the preceding tedium, so much the better, and if what we put in our mouths has to the highest degree those attractive features that make us want to chew and swallow it, so much better yet. Voilà, a Big Mac.

That's the tendency. It's not all there is to food. There are exceptions and countervailing forces. But the increase in the size and sophistication of the food industry, the progress in food engineering, the growth in the portions we eat, the effect that all this has had on average weight and health, all this amounts to an evident direction that the development of food is moving in.

It has led to grave cultural losses. There is to start with the loss of agriculture as a commendable form of culture, practices of raising plants and animals that are respectful of the environment, of the plants and animals, and of the workers. There is the impoverishment, if not the loss of the common understanding, of where the food has been grown and how it's been treated. The opaqueness of food production is of course just the shell of the gigantic machinery that has displaced the communities of farmers, butchers, bakers, and grocers we once knew. In the domestic sphere, the culture of cooking and eating has declined, yielding to the constant and ubiquitous availability of food. Regular and common meals have been reduced by snacks that are scattered and bites that are grabbed whenever.

Food used to be a thing that was the disclosure and conclusion of a rich and intelligible context of engagements. It's one of the pivotal conceits of the technological culture that the conclusion is crucial and the context dispensable. The conceit becomes practicable when the burdens of the context can be given over to an industrial machinery, and it seems commendable when the concluding goods appear to be superior in variety and attractiveness to the things they displace. What gets overlooked is the fact that the loss of context amounts to a cultural impoverishment.

Here again we have to be careful. In many instances, the loss of richness is outweighed by a gain of health and leisure. Getting water from the well or the fountain is a rich experience, to be sure. But water so obtained can be contaminated or dry up. To get enough water from springs and wells and meet sound sanitary standards is time consuming and a heavy burden for the household, still mostly run by women. Good judgment is needed to discern what should be left to the machinery of technology and what must be saved or retrieved for a life of excellence. 
Before I turn to the cures for the decline of the food culture, let me trace the more hidden pathology of the information culture. Information, like food, was once woven into the texture of everyday life, accessible and intelligible to all. Information came from nature, from the clouds that warned of rain, from the blossoms that foretold berries, from the tracks that pointed to game. It came from the stories of the elders, from the reports of those returning from gathering or hunting, and from the news conveyed by a member of the neighboring tribe.

Next came information that already required specialized instruction to be understood-notches on sticks, blazes on trees, cairns on hill tops. Then came writing and the expert knowledge of scribes, followed by literate communities that were vastly expanded through printing. Though reading and writing are demanding skills, they can be acquired by everyone and in the past gave everyone entry into a realm of information that was tangible in its ink and paper presence and intelligible to everyone in its form, though not, of course, in all of its contents.

Beginning, roughly, with the telegraph, an information machinery began to develop that became ever less intelligible as it became more powerful. Few people understood how sound from distant places became audible in their radios, fewer still how pictures could appear on their television tubes, and the machinery of today's computers and information links is incomprehensible to most users.

As in the case of food, the growing size and sophistication of the machinery have greatly increased the quantity and variety of information. Advocates of this development have predicted a citizenry that is better informed and more insightful and leads a richer cultural life. Supporters of social justice have been worried that the poor will be deprived of these blessings, and they have worked to level the digital divide. There can't be any doubt about the power and convenience of information technology, nor is there a question of its value to the sciences and the conscientious citizen.

But again, as in the case of food, the transformation of the ends that comes with the transformation of the means has too often been overlooked. Does it make a difference to the information contained in a book whether it comes to me in a codex or on a Kindle? The conveniences of a Kindle have been widely praised and appreciated. This past holiday season, Amazon has sold more electronic than hardcover books. To recognize the character of the electronic reading experience, we have to look ahead to the development of the device, the Kindle that makes the experience available. 
It's a sure bet that the austerity of the Kindle will yield to the richness of an iPhone. Not that the Kindle will replace the iPhone and its rivals. It's simply that users will expect additional conveniences, and competitors will oblige and even precede users. It will happen step by step. The Nook already has a color screen below the text display. Soon color will move up to render pictures and graphs contained in books. And if books can be read on a Kindle, why not articles? And if articles can be read, why can't films be watched? And so on to iPhone capabilities.

Imagine now a student reading Ulysses or The Man without Qualities. He is a little tired and comes to a passage that strikes him as tedious. He needs a refreshing break. Why not check email on the capable reading device? And then the preview of Griz-Cat game? The NFL game that is in progress. The weather....

When the student comes to, an hour has passed. It's obvious he won't get the reading done. But the tablet that has seduced him will help him out as well. There are summaries and race-gender-ethnicity critiques that will disburden him of the tedium of reading and thinking. When food is available abundantly, ubiquitously, and alluringly, people find themselves eating too much. They gain weight; their health suffers. When information is available abundantly, ubiquitously, and alluringly, people find themselves surfing too much. They become distracted; their knowledge suffers.

A book presents information in an austere and secluded form that aids attentive and sustained reading. The book by itself won't restore thoughtful reading. Its pre-electronic context was helpful too-the greater resistance and distances that had to be overcome to get to distractions most especially. But the book can be a helpful focal point and starting point for better reading.

Information technology can be a powerful instrument. It has supported astounding and admirable work in the physical sciences and new and interesting work in the social sciences. It's been a great convenience in the humanities though it has not occasioned any kind of flowering that I'm aware of. In the culture at large, the abundance of information has been no more beneficial than the abundance of food.

There has not been an overt catastrophe to be sure. Both food and information fulfill their basic task of keeping society going. Outrage would be misplaced. But sorrow about the enfeebling distensions of life is justified. What happened to food is happening to information. The 
refinements of information that the powerful machinery has made possible have obliged the stirrings of curiosity the way refined foods have answered the cravings of desire. Obesity and avoidable illness have their information analogues in distraction and avoidable ignorance.

We now recognize that overweight and obesity and the illnesses they bring with them are problems that require a public conversation and reasonable remedies. There are four measures that have received attention and may help us to cope with the abundance of food.

The first is lifting the hood of the food engine and beginning to understand how it works. One component of the engine is the corporate structures and policies that are pushing food. These include the employment of chemistry, the damage to the environment, and the devices of advertising and presentation. The necessary complement to corporate successes is the complicity of consumers, the chinks in our evolutionary armor of health, our vulnerability to the charms of availability, the more or less addictive cycle of craving, fulfillment, rising restlessness, more craving, and so on.

The second remedial measure is the recognition of partial alternatives to corporate machinery and consumer complicity. What's crucial here is the insight that preaching virtue is not enough and by itself can be worse than nothing. It leaves the preachers dispirited and the faithful defeated. What needs to be changed is the environment so that virtue has a chance to flourish. The production and availability of unhealthy food needs to be discouraged through public policy. Vice versa for healthy food.

Third and more concretely, we have to reweave the cultural context of food. The paths from the ground to the mouth need to be shortened and made evident as they are in the farm to college programs. The communal understanding of the origins and seasons of food has to be restored as it is in farmers' markets. And where possible, people should recover the skills and pleasures of gardening.

The last and perhaps least attended task is the rebuilding of the culture of the table, the common preparation of meals from basic and, whenever possible, local ingredients and the regular and pleasurable gatherings at the dinner table.

We should take similar steps to cope with the surfeit of information. So the first task is to teach students what's under the platforms that all the information is displayed on. Youngsters are often praised for their 
computer savvy. But this is the kind of knowledge teenagers have of their city. They know all the cool places and how to get from one to the other. They know how to ride bikes, drive cars and what to do about them if they crash. But they know little about the history of the city, its infrastructure, the zoning codes, city government, or mechanical engineering.

Students should know some Boolean algebra, electronics, and programming. They should understand the structure of the Internet, the interplay of regulation and corporation. Here too, they should learn why and how evolution has made us curious, what piques our curiosity, what satisfies it fleetingly and what enduringly.

Second, we have to understand that preaching against mindlessness and distraction is insufficient at best. We have to make classrooms places of concentration. Indiscriminate Wi-Fi availability is an invitation to distraction. Copious use of PowerPoint and slides scatters attention. Thoughtful speaking and listening are ancient human practices, less so than handling things and taking walks, but well-ingrained and rewarding as long as we don't let these talents atrophy the way we have let walking and handling wither away.

Third, information needs to be grounded in the actual and immediate world. Giving students a competent comprehension of the actual world is the task of general education. It's a task that's too often avoided by shaping general information after the pattern of the mechanization of information. Rather than teaching our students history and science, we teach them how to "think like a historian" or we teach them "the scientific method." Give them the means, they will take care of the ends - that's the assumption. But the ends to which the powerful means of information technology are actually put in contemporary culture should tell us that the ends, the content and substance of knowledge, require instruction and appropriation.

General education teaches a student the crucial dimensions and features of the actual world. At a time when we allow media technology constantly to insert itself between humans and reality, immediate contact with the world needs to be reinvigorated as well. We have to insist that students do what social scientists have ruefully come to call "groundtruthing," checking on the ground what satellites and surveys are displaying on a screen. Students need to be taught and encouraged to observe, investigate, describe, report, and analyze what immediately surrounds them.

There is also the homely reality of pen and paper, the skills of laying down 
in unique and artful traces of ink what truly matters and will likely endure and even be treasured-letters, journals, essays. Writing in longhand is like taking a walk or cooking a meal, a little slow and laborious compared with keyboarding just as walking and cooking are compared with driving and stopping for burgers and fries, but more sustaining as well.

Finally we should aim at the rebuilding of the culture of the word. The utility of information technology needs no justification or advocacy. It should remain a strand in the context of our lives. But within that context there has to be a central and secure place for reading and conversation, where electronic intrusions are kept at bay and our stages of discovery and pleasure-our books-surround us. We must make our students read Hamlet and Lear. But we should also encourage them to become life-long readers of Shakespeare.

\section{Notes}

1. Mark Bauerlein, The Dumbest Generation (New York: Tarcher, 2008); Maggie Jackson, Distracted: The Erosion of Attention and the Coming Dark Age (Amherst, NY; Prometheus, 2008); Susan Jacoby, The Age of Unreason (New York: Pantheon, 2008); Rick Sherman, Just How Stupid are We? (New York; Basic Books, 2008). What these books have in common is their attention to contemporary distraction and ignorance. They vary considerably in approach and quality.[Back]

[The Montana Professor 21.1, Fall $2010<\mathrm{http}: / /$ mtprof.msun.edu>]

\section{Contents | Home}

